\title{
Points, Points, and More Points: High School Grade Inflation and Deflation when Homework and Employability Scores are Included
}

\author{
Robert Griffin \\ Waterloo Community Schools, Iowa, USA \\ Matt Townsley \\ University of Norther Iowa, USA
}

\begin{abstract}
With a strong movement of schools starting to use standards-based grading practices, one of the aims of this study was to learn if traditional grading practices communicate grades that are accurate based on the students' learning of the course objectives. The purpose of this study was to determine the extent to which employability and homework scores within a traditional points- and percentages-weighted grading model inflates or deflates grades. This study analyzed 795 students' semester math grades at an urban high school to see if, and to what extent, students' grades were inflated or deflated due to including homework and employability scores in the grade. Final grades, which included homework and employability points, were compared to each student's overall summative assessment scores to determine grade inflation or deflation. The study also analyzed how changing grading practices to eliminate homework and employability points would impact the number of students that ultimately passed or failed the course. Results of this study indicated $336(43.2 \%)$ students had their grades inflated or deflated by $5 \%$ or more and $97(12.6 \%)$ students had their grades inflated or deflated by $10 \%$ or more, which is equivalent to moving up or down a full letter grade. School leaders should consider separately communicating academic and non-academic factors to minimize grade inflation/deflation in order to make decisions based upon grades more justifiable.
\end{abstract}

Keywords: standards-based grading, inflation, deflation, homework, employability

Failing grades is problematic for high school students as it relates to fulfilling graduation requirements. Grades are of critical importance for students in other ways as well because they hold so much power. For example, grades define student achievement and drive decisions such as academic awards, academic interventions, and advanced course placements (Feldman, 2018). Grades also influence athletic or extracurricular eligibility, employment/work permits/insurance rates, college acceptance, scholarships, and financial aid assistance. With the recent college-admissionstest-optional movement (Belasco et al., 2015; Rubin \& González, 2019), high school grades have grown in their importance as part of the post-secondary matriculation process. In a study including 47,303 students, results from Galla and colleagues (2019) suggested that high school grades were a better predictor of four-year college graduation rates than admissions tests, a theme recently confirmed by Allensworth and Clark (2020). With so much emphasis on grades, it is important to ensure they communicate their intended purpose, which is the extent to which students have achieved the course objectives (Allen, 2005; Brookhart et al., 2016; Kunnath, 2017a).

Yet, a review of research suggests grades in the past century have communicated a multidimensional construct containing both achievement and non-cognitive factors (Brookhart et al., 2016), which has made it challenging for school leaders to appropriately utilize grades in decision making. At the classroom level, teachers report utilizing factors such as tests, quizzes, homework completion, homework quality, work habits, and participation when determining a student's letter grade (Guskey \& Link, 2019; McMillan, 2018). When teachers mix achievement factors such as test scores with 
non-cognitive factors such as homework completion and participation, the result is a "hodgepodge" grade that does not accurately reflect what a student has learned (Brookhart, 1991). Secondary teachers, in particular, create categories for achievement and non-cognitive factors which are often weighted in order to determine a letter grade (McMillan, 2001; Russell \& Austin, 2010). Namely, Resh (2009) found that high school math and science teachers on average attributed $67 \%$ of their grades to academic achievement and the remaining $33 \%$ to non-cognitive factors such as effort.

Widespread grade inflation has been documented in high schools across the United States (Camara et al., 2003; Carr, 2004; Godfrey, 2011; Pope, 2006; Woodruff \& Ziomek, 2004). Grade inflation has typically been defined as increases in grade point average (GPA) when compared to student achievement measures such as standardized test scores. For example, Godfrey (2011) compared one state's high school grades to SAT scores to conclude that students with lower SAT scores are seeing greater increases in GPA. Furthermore, Pattison and colleagues (2013) argue that considering average GPAs as a primary means of assessing grade inflation may present an inaccurate representation due to ignoring GPA variance. Indeed, Algebra 1 end-of-course exam scores predict math ACT scores much better than do course grades in North Carolina within a 10-year time frame (Gershenson, 2018). As such, summative assessment and other exam scores separate from employability and homework, rather than grades as a whole, appear to be a construct worthy of further investigation. Based on the suggestions of future research offered by Zhang and Sanchez (2013), the current study sought to identify possible sources of grade inflation in high school settings.

Rather than comparing grades to standardized test scores, the purpose of this study was to determine the extent to which employability and homework scores within a traditional points- and percentages-weighted grading model inflate or deflate grades. The results of this study could assist school leaders who are interested in leading grading reform efforts, particularly those seeking empirical support of existing expert recommendations of minimizing the impact of employability and homework scores in determining students' final grades (O'Connor, 2009; Reeves et al., 2017; Vatterott, 2011).

\section{LITERATURE REVIEW}

\section{Grading and Subjectivity}

Grades should be fair, equitable, and useful to students, parents, and teachers as they are key in communicating student learning. To do so, experts suggest grades should be based on the achievement of learning goals (Bailey \& McTighe, 1996; Brookhart, 2004; Guskey, 1994) and primarily determined by summative assessments with behaviors reported separately from the final grades (O'Connor, 2009). Yet, scholars have found grading practices between teachers vary significantly (Brookhart, 2004; Guskey \& Link, 2019). Each teacher may utilize varying grading criteria even for courses that are taught within the same school (McMillan, 2001). In some cases, the difference between failing a class and making the honor roll simply depends on the teacher's grading policies (Reeves, 2008).

One way teachers' grading practices may differ is the categories in their grade books and the weighted average percentages assigned to each category. Several researchers suggest teachers include grading categories such as employability points that may impact a student's grade both positively and negatively (DiMaggio, 1982; Jussim, 1991; Keith et al., 1998; Roscigno \& Ainsworth-Darnell, 1999). In this study, employability points were defined by the school as points given to students as part of their grades that reflect $21^{\text {st }}$-century skills demonstrated within the classroom environment. These learning-enabling behaviors may include class participation, citizenship, and timeliness in submitting assignments (Guskey, 1994; 2020). While this approach to grading provides students with points for behaving in a desirable way alongside points for achieving the course standards as demonstrated on tests or projects, the result obfuscates the overall grade. Assessment expert Rick Stiggins and colleagues (1989) teased out this disconnect between theory and practice in stating, "Most teachers would agree that grades should be based on achievement; however not all would agree that grades should be based on achievement alone" (as cited by Brookhart, 2004, p. 115). For example, a study with 600 K-12 teachers found that while elementary teachers generally separated academic achievement and behaviors when assigning student grades, secondary teachers were more likely to include behavior and effort with a single grade (Guskey, 2009).

Subjectivity in grading is often challenging to overcome, and may unknowingly encourage teachers to use biased judgments with regards to grades. Feldman (2018) hypothesizes, "When teachers include in grades a participation or effort category that is populated entirely by subjective judgments of student behavior, they invite bias into their grading, particularly when teachers come from the dominant culture their students don't" (p. 54). Assessment and measurement 
experts have concluded that including behaviors, employability skills, and other non-cognitive factors mathematically introduces additional subjectivity and bias in grades (Guskey, 1994; Ornstein, 1994).

\section{Separating Grades}

Grading expert Thomas Guskey $(1994,1996,2020)$ suggests teachers should break up their grades to make grade books more reflective of learning. He suggests three major types of grading criteria that include product criteria, which reflect how well students have achieved the standards for the course; progress criteria, which document growth over time, and process criteria, which are learning enablers such as homework completion and work habits. When these criteria are reported independently, most notably reporting achievement separately from learning enablers (Brookhart et al., 2020), schools can more precisely communicate the student's strengths and areas of improvement. Separating grades is one component of a larger change some secondary schools are calling standards-based grading (Knight \& Cooper, 2018; Townsley, 2018; Townsley et al., 2019).

While these recommendations of separating grades have been present for over twenty years, little known research describes the quantitative impact of removing homework and employability scores to more accurately communicate student learning. The purpose of this study was to determine the extent to which employability and homework scores within a traditional points- and percentages-weighted grading model inflate or deflate grades. The questions driving this study were as follows:

1) How does including employability and homework scores within a traditional grading model inflate or deflate grades? Is there a significant difference between the final grade percentages and summative assessment percentages?

2) What percentage of students' grades were inflated or deflated due to the use of weighted homework and employability categories?

3) Were there any students that passed the class based on the overall grading including homework and employability categories who would have failed the class if they were graded based only on their summative assessment scores?

4) Were there any failing students who were negatively impacted by including homework and employability categories in the final grade determination?

\section{METHODS}

\section{Setting}

This study was conducted at Diversity High School (pseudonym) in the state of Iowa. Diversity High School serves about 900 students each year. As a state, $22.5 \%$ of Iowa's K-12 student population is non-White (Iowa Department of Education, 2015); however, Diversity High is located in an urban area with greater racial diversity. Diversity High School's student population is $49.3 \%$ White, 31.2\% Black, $11.2 \%$ Hispanic, and $8.3 \%$ other races such as American Indian and Asian students.

\section{Research Design}

To conduct this study, the researchers obtained university institutional research board (IRB) approval prior to collecting and analyzing all students' semester grades within Diversity High School. During the 2015-2016 school year, math teachers were committed to forming consistency for grading within the department, and as a result, the team uniformly separated their grade books into the categories summative assessments, homework, and employability. This consistency in the grading setup allowed the researchers to analyze ninth through twelfth grade student grades from 789 students enrolled in a math course. Ten students were removed from the study because they did not have a full set of recorded summative assessment scores. The remaining 779 students' grades were analyzed.

Teachers within this study gave students employability points each day based on their participation level in the class activities, attendance/tardies, and their level of social responsibility (not disruptive or disrespectful to staff or peers) during class time. Math teachers included daily assignments in the homework completion category and participation points were recorded in the employability category. Finally, all quizzes and test scores were recorded in the summative assessments category. The final grades were weighted with $70 \%$ of the overall grade based on summative assessments and $30 \%$ of the grade based on employability and homework scores. 
The following data points from math class grade books were analyzed in this study:

1) Final grade earned

2) Final grade percentage earned

3) Summative assessments percentage earned

4) Homework percentage earned

5) Employability skills percentage earned (e.g. arrive on time, attend class, participation, etc.)

After receiving IRB and school district approval, the data points were extracted directly from the district's electronic grade book with anonymous student and teacher identifiers.

\section{Data Analysis}

To answer research question number one, after the students' semester grades were charted, each student's final grade percentage was compared to their summative assessment percentage to see if and how much of the final grade was inflated or deflated with the inclusion of homework and employability categories. For example, a student's final grade of $85 \%$ and a summative assessment grade of $80 \%$ would indicate that the student's overall grade was inflated by $5 \%$ when non-cognitive factors of employability and homework were added to the overall grade. To identify if there were statistically significant differences $(p<.001)$ between the final grade and summative assessment grades, the researchers compared the means of these grading categories. Using a paired $t$-test ( 2 tailed), each group's equality of means was analyzed to discover if there was a statistically significant result $(p<.001)$.

Next, to answer research question two, the number of students with higher final grades than their summative assessment grades were tallied. This total was used to calculate the percent of students' grades inflated due to the use of weighted homework and employability categories. Similarly, students with lower final grades when compared to their summative assessment grades were counted and calculated to find the percent of students' grades that were deflated due to the use of homework and employability categories.

To answer research question three, the researchers analyzed if any students who failed the class based on the overall grade including homework and employability categories would have passed the class if they were graded based only on their summative assessment scores. Through this analysis, the researchers looked for any student's final failing grades (less than 59.5\%) while also having a summative assessment grade of passing (above 59.5\%). Finally, to answer question four, the researchers counted students who passed the class based on the overall grading policy that included homework and employability categories but would have failed the class if they were graded based only on their summative assessment scores. These grades were recorded by finding students with final passing grades (greater than 59.5\%) that also had a failing summative assessment grade (below 59.5\%).

\section{RESULTS}

\section{Research Question 1: Grade Inflation and Deflation When Including Employability and Homework Scores}

As noted in Table 1, there were statistically significant differences when comparing the means between students' summative assessment percentage grades $(M=67.35, S D=18.08)$ and their final grade percentage grades $(M=68.84, S D$ $=17.19)$ in their math class $\left(t_{778}=6.84, p<.001\right)$. While these results were statistically significant, the mean difference between the summative assessment grade percentage and final grade percentage was only $1.49 \%$.

While the average inflation/deflation of the grade was relatively small $(1.49 \%)$, it is important to note this was the average. The total combined percent of deflation almost cancels out the total combined percent of inflation. To adjust the statistics based on this effect, the researchers also determined the absolute values of both positive and negatively impacted grades. As a result, the average inflation/deflation of the grades using the absolute values was 5.0\%. This means the average difference between summative assessment results and final grades was a half a letter grade. For example, a student with a letter grade of $89 \% \mathrm{~B}+$ for a summative assessment grade may have received as high as $94 \%$ A- or as low as $84 \%$ B when employability and homework scores were factored into the final grade. 
Table 1

Paired Samples T-Test Results Comparing Summative Assessment and Overall Percent

\begin{tabular}{|c|c|c|c|c|c|c|c|c|c|c|}
\hline \multirow{3}{*}{ Outcome } & \multicolumn{2}{|c|}{$\begin{array}{c}\text { Summative } \\
\text { Assessments } \\
\text { Percent }\end{array}$} & \multicolumn{2}{|c|}{ Final Percent } & \multirow{3}{*}{$N$} & \multirow{2}{*}{\multicolumn{2}{|c|}{$\begin{array}{l}\text { 95\% CI for Mean } \\
\text { Difference }\end{array}$}} & \multirow{3}{*}{$t$} & \multirow[b]{2}{*}{$d f$} & \multirow{3}{*}{$\frac{\text { Sig. (2 tailed })}{000^{*}}$} \\
\hline & $M$ & $S D$ & $M$ & $S D$ & & & & & & \\
\hline & 67.35 & 18.08 & 68.84 & 17.19 & & -1.92 & -1.06 & & 778 & \\
\hline
\end{tabular}

${ }^{*} p<.001$

\section{Research Question 2: Percentage of Students' Grades Inflated or Deflated When Including Employability and Homework Scores}

In addition to understanding the average inflation or deflation percentage, the researchers also sought to determine the percentage of students with inflated or deflated grades when accounting for employability and homework scores. Of the students at Diversity High, 479 students $(61.5 \%)$ had inflated grades when homework and employability points were included in their math grade. Slightly over one-third (299 or 38.4\%) had deflated grades and only one student's grade remained unchanged. Specifically, 38.4\% of the students had better summative assessment percentages compared to their final grades, and as such, were negatively impacted by having homework and employability scores included in their overall grades.

It is worth pointing out that $336(43.2 \%)$ students in this study had their grade inflated or deflated by $5 \%$ or more, which equates to moving up or down at least half a letter grade. For example, this might mean a student moves from $70 \%$ C- to $75 \%$ C or from a $90 \%$ A- to an $85 \%$ B. Furthermore, $97(12.6 \%)$ students in this study had their grades inflated or deflated by $10 \%$ or more, which is the equivalent to moving a full letter grade. In the latter scenario, a student could move from a $60 \%$ D- to a $70 \%$ C- or jump from an $80 \%$ B- to a $90 \%$ A-. In the most extreme student cases within this study, grades were deflated by $18.26 \%$ and inflated by $18.95 \%$, respectfully.

Figure 1 shows a visual representation of the inflation and deflation of grades for all 779 students in this study. Each blue line within Figure 1 shows how much grades were inflated or deflated through the inclusion of employability and homework scores in the grade book. The longer the vertical line, the greater the degree of inflation or deflation for the student's grade. Figure 1 shows the degree to which homework and employability points improved or hindered students' final grades when compared to their summative assessment grade. A blue line above zero indicates the grades were positively impacted, or inflated, by including homework and employability, whereas a line below zero shows the student grades were negatively impacted, or deflated.

Figure 1.

\section{Inflation/Deflation of Grades when Including Homework and Employability Scores}

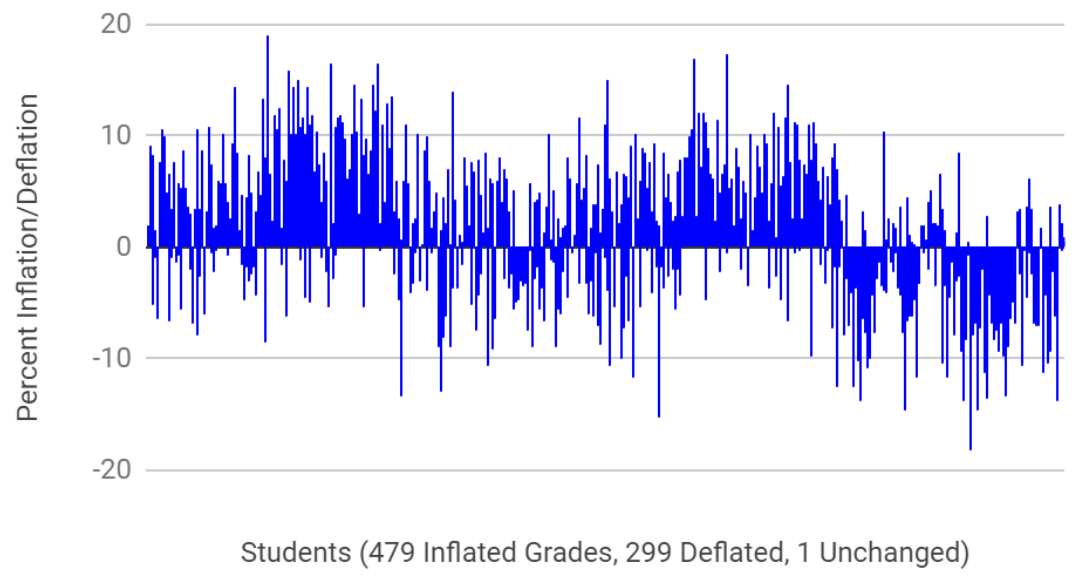

In this study, the majority of students' $(61.5 \%)$ final grades were positively impacted when homework and employability points were included in the grade compared to grades based solely upon students' performance on 
summative assessments (Figure 2). In this grading system, 69 students earned an A when including summative assessments, homework, and employability. If homework and employability points were removed from the grading components, only 65 students would have earned an A, as seen in Figure 2.

Figure 2.

\section{Grading Comparison When Including Assessment Only vs. Including Homework and Employability.}

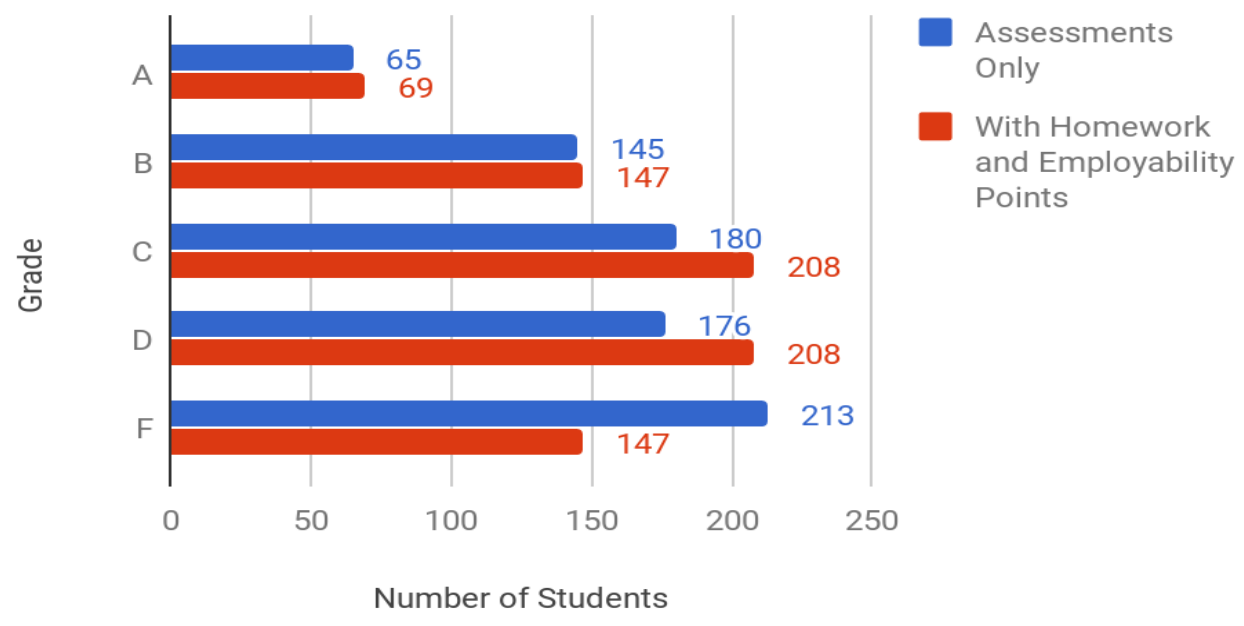

\section{Research Question 3: Students Who Passed the Class Through Including Homework and Employability Scores}

According to Figure 2, most of the student grades were higher with the inclusion of homework and employability points in the final grade. For example, there are more A's, B's, C's and D's and fewer failing grades when these components are included in the grade compared to if the grade were based only on summative assessments. Most of the overall grades in Figure 2 show improvement when comparing summative assessment grades and final grades. This is most significant for the students who would have received failing $(F)$ grades if using summative assessment-only grades. With the current grading system including employability and homework scores, as seen in Figure 2, 147 students failed the course compared to the 213 students who would have failed the class if the teacher only based grading on summative assessment scores. Stated differently, 66 students' grades were inflated to the passing mark with the inclusion of homework and employability points even though they did not demonstrate overall proficiency in the course objectives. Furthermore, there were 74 students with passing (above 59.5\%) final grades, even though they had a failing summative assessment grade (below 59.5\%), as displayed in Figure 3. Figure 3 also shows the students who would have failed the class if they were only graded using summative assessments, but due to homework and employability points being included in the final grade, passed the course. The blue line in Figure 3 indicates the percentage grade the student received on summative assessments, and the red line shows the impact of homework and employability points added into the overall grade that resulted in a passing grade for the course.

Considering individual student cases provides another perspective on students who only passed the class due to the inclusion of employability and homework scores, and so it is worth mentioning one particular student case. On the most extreme end, Student 128 scored 59.74\% (D-) on the final grade despite a failing summative assessment average of $44.73 \%$. This student's grade was inflated by $15.01 \%$ with the inclusion of homework and employability scores. 
Figure 3.

Students with Failed Summative Assessment Percentage and Passing Overall Grade

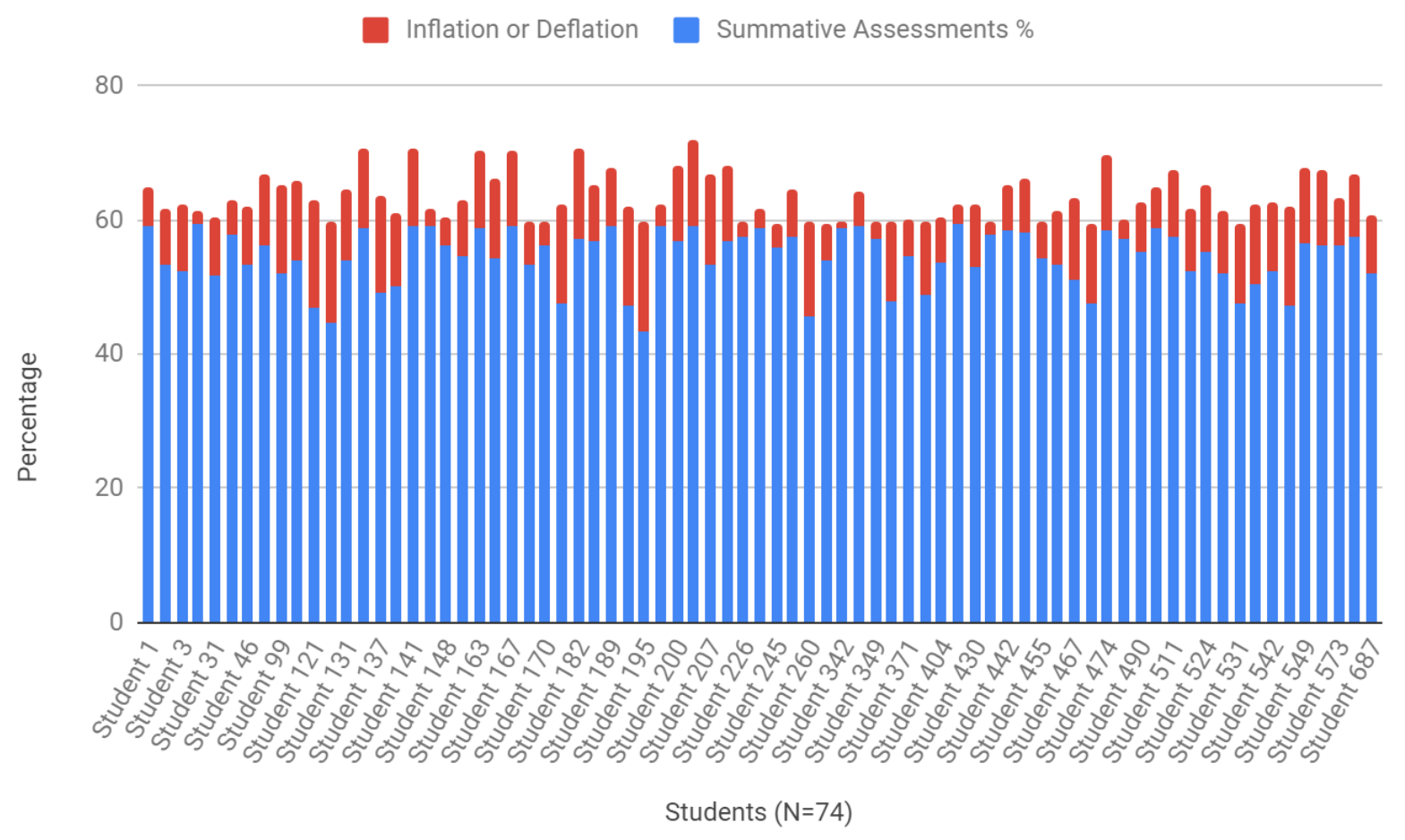

\section{Research Question 4: Students Who Failed the Class Through Including Homework and Employability Scores}

There were 10 students with passing (above 59.5\%) summative assessment grades and a failing final grade (below $59.5 \%)$. This compares to 74 students $(10 \%)$ who passed the class but would have failed based on their summative assessment scores. Therefore, many more students benefited from inflated grades by passing the class with the inclusion of homework and employability points even though the students had not mastered the course objectives content based on their summative assessment scores. On the most extreme end, Student 712 scored $70.8 \%$ on their summative assessments and failed the class with a $56.08 \%$ due to lower employability and homework scores. Overall, these 10 students make up about $1 \%$ of the study sample; therefore, there was only a very small percentage of students in this scenario.

\section{DISCUSSION \& IMPLICATIONS}

The teachers in this study weighted their grades such that $70 \%$ of the overall grade was based on summative assessments and $30 \%$ of the grade was based on employability and homework. This means that the maximum amount of inflation or deflation of the overall grade based on employability and homework points would be $30 \%$. Weighting grades is one strategy teachers use within the traditional grading model in an attempt to continue grading practices familiar to parents and students while keeping a majority focus on the learning outcomes based on summative assessment measures. Even with these measures in place at Diversity High, there was a significant impact on grades with $43.2 \%$ of the grades inflated or deflated by at least half a letter grade. Further, $12.6 \%$ of the grades were inflated or deflated by a full letter grade.

Grading experts agree that the purpose of grades is to communicate learning. Therefore, based on the results of this study, it is important to consider why teachers continue to include employability and homework points in the grade if it makes the final grade an inaccurate representation of the students' content knowledge. First, it is possible that teachers feel the pressure of passing students to raise graduation rates. This is especially true in diverse urban areas that focus on reaching graduation rates seen in less diverse communities (Anagnostopoulos, 2003). As a result, teachers may keep employability points and homework as part of the grade to propel students that normally would have failed the class up to the passing mark. Furthermore, some students are accustomed to playing "the game of school" (Fried, 2005), in which 
earning points supersedes learning in their minds; therefore, points awarded for employability and homework could be viewed favorably in their daily decision-making process.

For example, in this study, the majority of the grades (61.5\%) were inflated, and 66 students (8\%) passed the class despite not achieving a passing level of understanding of the course objectives based on assessment scores. This may be possible evidence of grade inflation due to external perceptions from other teachers and school leaders (Kunnath, 2017b). These pressures could be impacting teachers' grading choices, and as a result, they may be using non-academic factors such as homework and employability categories to help inflate the grades to create a better image for the district and the community.

Another possible reason that teachers keep employability and homework points in the grade book is to prepare students for future employment (Merchant, et al., 2018). As educators continue to understand the responsibilities of teaching the whole child (Noddings, 2005), they find themselves responsible for teaching academic course objectives while simultaneously preparing students for future employment. In fields such as career and technical education, experts argue that both are equally important and therefore teachers are responsible for teaching employment skills in conjunction with academic course objectives (Lichty \& Retallick, 2017). Perhaps the teachers in this study believe they are holding students accountable for student participation in class, attendance, and social behaviors by including these factors in their overall grades. Additional research is needed to understand why high school teachers include employability and homework points in the determination of grades despite their inflation and deflation effects on students.

Teachers may claim they are helping students learn the importance of these skills and how they will impact their future employment; however, simply including the skills within the student grade is not an effective method for students to learn these skills. Some students come to school without these employability skills and therefore it becomes the role of teachers to assist learners in developing them. If teachers want to continue to keep these skills in the overall grade, employability skills must be taught as part of the content to assure no students are disadvantaged in their final grades for skills they weren't taught. Furthermore, teachers must find ways to teach these employment skills similarly to teaching math skills so students with gaps in this area can improve and in turn, maintain an appropriate grade (Wentzel, 1989).

Another reason teachers might keep homework points in the grade book is they believe it holds students accountable for completing the practice needed to master the course objectives (Cooper, 1994). Teachers may argue that there is a strong relationship between homework and summative assessment scores; however, in this study; the correlation between homework and summative assessment scores was only a moderate positive correlation of $r=0.479$. This data does not suggest that completing homework ensures high summative assessment scores. Therefore, teachers should consider evaluating homework assigned to ensure it is strongly aligned with course objectives assessed. When this alignment is present, students may better understand how feedback and practices on homework will improve their summative assessment scores.

In addition to the possible causes for grade inflation, researchers and practitioners should be aware of the potential impact of the results from this study. Because grades define student achievement and drive decisions such as academic awards, academic interventions, and advanced course placements (Feldman, 2018), the stakes are important for high schools to "get grading right." Nearly half of the students had their math grades inflated or deflated by a half of a letter (plus or minus), and over one in ten students had their grades inflated or deflated by a full letter grade. Absent college admissions test scores as part of a growing national trend (Belasco et al., 2015; Rubin \& González, 2019), high school grades will become an even more important factor when considering admissions decisions and perhaps merit-based scholarship decisions. Nearly $40 \%$ of the students in this study had better summative assessment percentage grades compared to their final grades, implying that the inclusion of homework and employability grades has the potential to negatively students in the college admissions and scholarship process. Alternatively, the majority of students' $(61.5 \%)$ final grades were positively impacted when homework and employability points were included in the grade compared to if teachers only based grades upon their final grades on summative assessments. These students may be benefitting from "hodgepodge" grading practices, and yet astute parents may realize including points for employability skills, while inflating their student's grades, is ultimately self-serving. The aforementioned scenario may shed light on why previous research documents parents' concerns with moving away from traditional grading practices (Frankin et al., 2016; Townsley et al., 2019).

Rather than merely combining weighted categories into a final grade, one suggestion for high school teachers would be to report employability and homework performance as a separate grade as is the case in many elementary schools (Guskey, 2009). For example, elementary report cards often communicate student performance levels with a scale such as met standard, approaching standard, and standard not net. In a separate section of the report card, a student's employability or $21^{\text {st }}$-century skills are also reported. Using this approach, employability skills are emphasized along with 
the levels of learning academic standards. When these factors are reported in a separate category that do not affect the final grade, teachers can better communicate students' knowledge and skills.

Some stakeholders might argue that including employability and homework scores assists students who do not perform well on tests (Vatterott, 2011). Since these students are not good "test takers," their final grades will be lower if grades are only based on summative assessment scores. Yet, some experts suggest students' test anxiety could be lowered when they are given multiple opportunities to show their mastery of the course objectives, such as the case of retaking assessments (Marzano \& Heflebower, 2011; O’Connor, 2009; Wormeli, 2011). These grading experts also argue that students learn at different rates and paces; therefore, grading practices ought to reflect this reality, too. As such, homework and employability skills, which are intended for students to practice and make mistakes early in the learning process, ought to be communicated separately from product criteria such as summative assessments.

\section{CONCLUSIONS}

Building upon the ideas from the literature, grades should communicate homework and employability grades separate from achievement (Brookhart et al., 2016; Guskey, 1994; Muñoz \& Guskey, 2015; O'Connor, 2009). In this new way of thinking about grading, a student with A-level skills based on the product criteria demonstrated on summative assessments would also receive a final letter grade of an A. One such method of grading for districts or teachers to consider might be standards-based grading. Standards-based grading is intended to be a more accurate system in terms of communicating the product or how well a student understands the course objectives (Muñoz \& Guskey, 2015; Knight \& Cooper, 2019; Townsley, 2018). When teachers employ standards-based grading, stakeholders such as parents, teachers, students, or colleges looking at class grades would know a student's level of mastery within that subject. Furthermore, if these same stakeholders looked at the details of the grade, they would see which standards the student met, which ones they were approaching, and finally, which standards they did not meet (Guskey, 1994, 2020). This allows teachers, students, and parents alike to see the learning that has already occurred and pinpoint skills the student could continue to improve upon. School leaders seeking to provide a rationale for standards-based grading may benefit from understanding the effects of grade inflation and deflation on students noted in this study.

The results of this research suggest non-academic factors included in a student's grades can have a strong impact on the final letter grade. For example, when non-academic factors (behavior, participation, attendance, homework completion) count for as much as $30 \%$ of the final grade and students are given maximum points for these factors, this may increase grades from a B to an A. On the other hand, students not earning points for these factors may drop full letter grades or more. By taking out these non-academic factors from the grade and reporting them separately, the achievement grades will be more accurate rather than being subject to inflation or deflation from homework and employability scores. In addition, separating these factors may be a way of breaking the cycle of grades that have, for the past century, been construed as a multidimensional construct (Brookhart et al., 2016). Grades in high school settings are often used for highstakes decisions; therefore, minimizing inflation and deflation by separating academic and non-academic factors, in the spirit of standards-based grading, may make these decisions more justifiable. The result is more accurate and sensible grades being communicated to the student, parent, colleges, and employers, which is the point of grading.

\section{REFERENCES}

Allen, J. D. (2005). Grades as valid measures of academic achievement of classroom learning. The Clearinghouse, 78(5), 218-223.

Allensworth, E. M., \& Clark, K. (2020). High school GPAs and ACT scores as predictors of college completion: Examining assumptions about consistency across high schools. Educational Researcher, 49(3), 198-211.

Anagnostopoulos, D. (2003). The new accountability, student failure, and teachers' work in urban high schools. Educational Policy, 17(3), 291-316.

Bailey, J., \& McTighe, J. (1996). Reporting achievement at the secondary level: What and how. ASCD-yearbook, 119140.

Belasco, A. S., Rosinger, K. O., \& Hearn, J. C. (2015). The test-optional movement at America's selective liberal arts colleges: A boon for equity or something else? Educational Evaluation and Policy Analysis, 37(2), 206-223.

Brookhart, S. M. (1991). Grading practices and validity. Educational Measurement: Issues and Practice, 10(1), 35-36. Brookhart, S. M. (2004). Grading. Upper Saddle River, NJ: Merrill. 
Brookhart, S. M., Guskey, T. R., Bowers, A. J., McMillan, J. H., Smith, J. K., Smith, L. F., Stevens, M. T., \& Welsh, M. E. (2016). A century of grading research: Meaning and value in the most common educational measure. Review of Educational Research, 86(4), 803-848.

Brookhart, S. M., Guskey, T. R., McTighe, J., \& Wiliam, D. (2020). Eight essential principles for improving grading. Educational Leadership, 78(1). Online exclusive.

Camara, W., Kimmel, E., Scheuneman, J., Sawtell, E. A. (2003). Whose grades are inflated? (Research Report No. $2003-$ 4). New York, NY: College Board.

Carr, P. C. (2004). The NAEP high school transcript study. Education Statistics Quarterly, 6, 4-5.

Cooper, H. (1994). Homework research and policy: A review of the literature. Research/Practice, 2(2), 1-10.

DiMaggio, P. (1982). Cultural capital and school success: The impact of status culture participation on the grades of U. S. high school students. American Sociological Review, 47(2), 189-201.

Feldman, J. (2018). Grading for equity: What it is, why it matters, and how it can transform schools and classrooms. Corwin Press.

Frankin, A., Buckmiller, T., \& Kruse, J. (2016). Vocal and vehement: Understanding parents' aversion to standards-based grading. International Journal of Social Science Studies, 4(11), 19-29.

Fried, R. (2005). The game of school: Why we play it, how it hurts kids, and what it will take to change it. Jossey-Bass.

Galla, B. M., Shulman, E. P., Gardner, M., Hutt, S. J., Goyer, J. P., D’Mello, S. K., Finn, A. S., Duckworth, A. L. (2019). Why high school grades are better predictors of on-time college graduation than are admissions test scores: The roles of self-regulation and cognitive ability. American Educational Research Journal, 56(6), 2077-2115.

Gershenson, S. (2018). Grade inflation in high schools (2005-2016). Thomas B. Fordham Institute.

Godfrey, K. (2011). Investigating grade inflation and non-equivalence (Research Report 2011-2). New York, NY: College Board.

Guskey, T. R. (1994). Making the grade: What benefits students. Educational Leadership, 52(2), 14-20.

Guskey, T. R. (2009). Bound by tradition: Teachers' views on crucial grading and reporting issues. Online submission.

Guskey, T. R., \& Link, L. J. (2019). Exploring the factors teachers consider in determining students' grades. Assessment in Education: Principles, Policy \& Practice, 26(3), 303-320.

Guskey, T. R. (2020). Breaking up the grade. Educational Leadership, 78(1), 40-46.

Iowa Department of Education. (2015). 2015-2016 Iowa public school district PreK-12 enrollments by district, grade, race and gender. Accessed 8 February 2020, https://educateiowa.gov/documents/public-district/2018/07/2015-2016iowa-public-school-district-prek-12-enrollements-district

Jussim, L. (1991). Grades may reflect more than performance: Comment on Wentzel (1989). Journal of Educational Psychology, 83(1), 153-155. https://doi.org/10.1037/0022-0663.83.1.153

Keith, T. Z., Keith, P. B., Quirk, K. J., Sperduto, J., Santillo, S., \& Killings, S. (1998). Longitudinal effects of parent involvement on high school grades: Similarities and differences across gender and ethnic groups. Journal of School Psychology, 36(3), 335-363. https://doi.org/10.1016/S0022-4405(98)00008-9

Knight, M. \& Cooper, R. (2019). Taking on a new grading system: The interconnected effects of standards-based grading on teaching, learning, assessment, and student behavior. NASSP Bulletin, 103(1), 65-92.

Kunnath, J. (2017a). Creating meaningful grades. Journal of School Administration Research and Development, 2(1), 53 56.

Kunnath, J. (2017b). Teacher grading decisions: Influences, rationale, and practices. American Secondary Education, $45(3), 68-88$.

Lichty, J. A., \& Retallick, M. S. (2017). Iowa agricultural educators' current and perceived grading practices. Journal of Research in Technical Careers, 1(1), 11.

Marzano, R., \& Heflebower, T. (2011). Grades that show what students know. Educational Leadership, 69(3), 34-39.

McMillan, J. H. (2001). Secondary teachers' classroom assessment and grading practices. Educational Measurement: Issues and Practice, 20(1), 20-32.

McMillan, J. (2018). Surveys of teachers' grading practices and perceptions. In T. R. Guskey and S. M. Brookhart (Eds.), What do we know about grading: What works, what doesn't, and what's next (pp. 113-144). ASCD.

Merchant, S., Klinger, D., \& Love, A. (2018). Assessing and reporting non-cognitive skills: A cross-Canada survey. Canadian Journal of Educational Administration and Policy, 187.

Muñoz, M. A. \& Guskey T.R. (2015). Standards-based grading and reporting will improve education. Phi Delta Kappan, 96(7), 64-68.

Noddings, N. (2005). What does it mean to educate the whole child? Educational Leadership, 63(1), 8-13. 
O’Connor, K. (2009). Reforming grading practices in secondary schools. Principal's Research Review, 4(1), 1-7.

Ornstein, A. C. (1994). Grading practices and policies: An overview and some suggestions. NASSP Bulletin 78(561), 5564.

Pattison, E., Grodsky, E., \& Muller, C. (2013). Is the sky falling? Grade inflation and the signaling power of grades. Educational Researcher, 42(5), 259-265.

Pope, J. (2006, November 18). Admissions boards face "grade inflation." The Washington Post. Retrieved from http://www.washingtonpost.com/wp-dyn/content/article/2006/11/18/AR2006111800473_pf.html

Reeves, D. B. (2008). Leading to change/effective grading practices. Educational Leadership, 65(5), 85.

Reeves, D., Jung, L. A., \& O'Connor, K. (2017). What's worth fighting against in grading? Educational Leadership, 74(8), 42-45.

Resh, N. (2009). Justice in grades allocation: Teachers' perspective. Social Psychology of Education, 12, 315-325.

Roscigno, V. J., \& Ainsworth-Darnell, J. W. (1999). Race, cultural capital, and educational resources: Persistent inequalities and achievement returns. Sociology of Education, 158-178.

Rubin, P. G., \& González Canché, M. S. (2019). Test-flexible admissions policies and student enrollment demographics: Examining a public research university. The Review of Higher Education, 42(4), 1337-1371.

Russell, J. A., \& Austin, J. R. (2010). Assessment practices of secondary music teachers. Journal of Research in Music Education, 58(1), 37-54.

Townsley, M. (2018). Mastery-minded grading in secondary schools. School Administrator, 75(2), 16-21.

Townsley, M., Buckmiller, T., \& Cooper, R. (2019). Anticipating a second wave of standards-based grading implementation and understanding the potential barriers: Perceptions of high school principals. NASSP Bulletin, 103(4), 281-299.

Vatterott, C. (2011). Making homework central to learning. Educational Leadership, 69(3), 60-64.

Wentzel, K. R. (1989). Adolescent classroom goals, standards for performance, and academic achievement: An interactionist perspective. Journal of Educational Psychology, 81(2), 131-142. https://doi.org/10.1037/00220663.81.2.131

Woodruff, D. J., \& Ziomek, D. L. (2004). Differential grading standards among high schools (ACT Research Report Series 2004-2). Iowa City, IA: ACT.

Wormeli, R. (2011). Redos and retakes done right. Educational Leadership, 69(3), 22-26.

Zhang, Q., \& Sanchez, E. I. (2013). High school grade inflation from 2004 to 2011. (ACT Research Report Series 20132). Iowa City, IA: ACT.

ROBERT GRIFFIN, Ed.D, is an Instructional Coach in the Special Education Department at Waterloo Community Schools in Waterloo, Iowa. His major research interests lie in the area of grading, equity, secondary and special education research. Email: robgrif32@gmail.com

MATT TOWNSLEY, EdD, is an Assistant Professor of Educational Leadership in the College of Education, University of Northern Iowa, Cedar Falls, IA. His major research interests lie in the areas of educational leadership, school improvement and standards-based grading. Email: matt.townsley@,uni.edu 